\title{
ANALISIS INSTRUMEN TES HASIL BELAJAR BERBASIS HIGHER ORDER THINKING SKILL (HOTS)
}

\author{
$\operatorname{Herman}^{1}$ \\ Abd Rahman Rahim ${ }^{2}$ \\ Andi Sukri Syamsuri ${ }^{3}$ \\ ${ }^{1}$ SDN 205 Inpres Moncongjai Kabupaten Maros, Indonesia \\ ${ }^{2,3}$ Universitas Muhammadiyah Makassar, Indonesia \\ hermanspd75@gmail.com ${ }^{1)}$ \\ rahman@unismuh.ac.id ${ }^{2 *}$ \\ andhies@unismuh.ac.id ${ }^{3)}$
}

\begin{abstract}
Abstrak
Penelitian ini bertujuan untuk mendeskripsikan: (1) Tingkat kualitas soal tes hasil belajar bahasa Indonesia buatan guru SDN 205 Inpres Moncongjai Kabupaten Maros ditilihat dari kaidah penulisan soal yang baik, dan (2) Tingkat kualitas soal tes hasil belajar bahasa Indonesia buatan guru SDN 205 Inpres Moncongjai Kabupaten Maros ditilihat dari HOTS. Penelitian ini dlaksanaan di SDN 205 Inpres Moncongjai, Kabupaten Maros menggunakan metode kuantitaif dengan teknik dokumentatif terhadap soal bahasa Indonesia buatan guru kelas pada tahun pelajaran 2018/2019. Data dianalaisis menggunakan analisis kuantitatif berupa telaah kaidah penulisan soal dan tingkat HOTS soal yang dibuat guru. Hasil penelitian menunjukkan bahwa tingkat kualitas soal tes hasil belajar bahasa Indonesia buatan guru SDN 205 Inpres Moncongjai Kabupaten Maros ditilihat dari kaidah penulisan soal yang baik masih rendah. Kaidah penulisan soal dominan tidak sesuai adalah (1) kaidah soal harus menggunakan bahasa yang sesuai kaidah bahasa Indonesia (semua aspek) (2) pilihan jawaban harus homogen dan logis ditinjau dari segi isi materi. Soal tes hasil belajar bahasa Indonesia buatan guru SDN 205 Inpres Moncongjai Kabupaten Maros masih sangat sedikit yang berbasis HOTS. Pada level tingkat berpikir soal umunya masih berada pada ingatan, pemahamn dan penerapan, masih sangat sedikit yang berbasis HOTS.
\end{abstract}

Kata Kunci: Tes Hasil Belajar, Higher Order Thinking Skill (HOTS)

Published by:

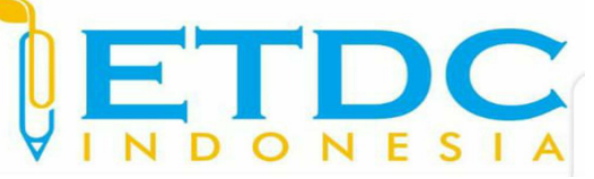

Copyright (C) 2021 The Author (s)

This article is licensed under CC BY 4.0 License

(cc) $\mathrm{BY}$ 


\section{ANALISIS INSTRUMEN TES HASIL BELAJAR BERBASIS HIGHER ORDER THINKING SKILL (HOTS)}

\section{Pendahuluan}

Kurikulum, proses pembelajaran, dan penilaian merupakan tiga komponen penting dalam pembelajaran. Ketiga komponen tersebut saling berkaitan antara satu dengan yang lainnya. Kurikulum merupakan jabaran dari tujuan pendidikan nasional yang menjadi landasan program pembelajaran. Proses pembelajaran merupakan upaya untuk mencapai kompetensi yang dirumuskan dalam kurikulum. Sementara itu, penilaian kelas dilakukan untuk mengukur dan menilai tingkat pencapaian kompetensi oleh siswa. Penilaian juga digunakan untuk mengetahui kekuatan dan kelemahan proses pembelajaran, sehingga dapat dijadikan dasar pengambilan keputusan. Oleh sebab itu, di samping kurikulum yang baik dan proses pembelajaran yang bermakna diperlukan adanya sistem penilaian yang baik, terencana dan berkesinambungan pada setiap satuan pendidikan.

Dalam rangka meningkatkan mutu pendidikan dan mutu sumber daya manusia sesuai dengan standar kompetensi yang ditetapkan secara nasional, maka perlu dilaksanakan sistem penilaian yang baik dan terencana. Hal ini ditegaskan di dalam Undang-Undang Nomor 20 Tahun 2003 tentang, dan perbaikan Sistem Pendidikan Nasional pasal 58 ayat 1 bahwa dalam rangka pencapaian standar kompetensi siswa, evaluasi hasil belajar siswa dilakukan oleh pendidik untuk memantau proses, kemajuan hasil belajar peserta didik secara berkesinambungan. Penilaian terhadap pencapaian kompetensi perlu dilakukan secara objektif berdasarkan kinerja peserta didik dengan bukti penguasaan mereka terhadap pengetahuan, ketrampilan, dan nilai sikap sebagai hasil belajar. Dengan demikian, pada hakikatnya penilaian terhadap pembelajaran siswa dimulai dan dititikberatkan pada penilaian oleh guru di kelas. Penilaian kelas (classroom-based assesment) adalah penilaian yang dilakukan oleh guru untuk mengetahui pencapaian kompetensi siswa, keberhasilan proses pembelajaran, dan penentuan kenaikan kelas.

Berdasarkan uraian di atas, maka guru wajib mengembangkan tes/soal atau instrumen berupa tes untuk mengemban tugas tersebut di atas. Oleh karena itu, guru diharapkan mempunyai keterampiran yang cukup untuk membuat soal yang baik agar tujuan yang akan dinilai dapat terukur dengan baik. Menulis soal, tentu bukan persoalan sepele karena tes memiliki berbagai kriteria. Apalagi ditekannya pemanfaatan soal berpikir tingkat tinggi atau Higher Order Thinking Skill (HOT). Tidak dapat dipungkiri bahwa, masih banyak guru yang kurang terampil membuat tes atau soal terlebih lagi soal berbasis HOTS. Salah satu penyebanya 
karena selama ini tidak semua guru tidak terbiasa menulis soal yang baik. Selama ini lebih banyak soal dibuat terpusat dan guru hanya menggunakan saja. Hal ini mengakibatkan guru kurang terlatih dalam membuat soal pada mata pelajaran yang dijarkan masing-masing.

Masalah yang biasa dihadapi penulis soal adalah isi soal yang berkaitan dengan HOTS, konstruk soal, dan bahasa soal masih banyak yang tidak sesuai dengan kriteria penulisan soal. Berdasarkan hal di atas maka sangat penting untuk meneliti kesesuaian kriteria penulisan soal dengan soal buatan guru dalam kaitannya dengan soal HOTS. Oleh karena itu, penulis bermaksud melakukan penelitian mengenai analisis kualitatif soal tes hasil belajar buatan guru yakni analisis soal tes hasil belajar berbasis Higher Order Thinking Skill (HOTS) buatan guru SDN 205 Inpres Moncongjai Kabupaten Maros. Penelitian ini diharapkan dapat memberi sumbangan pemikiran bagi guru agar dapat mengembangkan kemampuan membuat soal yang baik berdasarkan kriteria dan berbasis HOTS.

\subsection{Hakikat Tes}

Secara umum orang hanya mengidentikkan kegiatan evaluasi sama dengan menilai, karena aktifitas mengukur biasanya sudah termasuk didalamnya. Pengukuran, penilaian dan evaluasi merupakan kegiatan yang bersifat hierarki. Evaluasi berhubungan dengan keputusan nilai (value judgement). Stufflebeam dalam dalam Makmun (2016) memengemukakan bahwa : educational evaluation is the process of delineating, obtaining,and providing useful, information for judging decision alternatif. Dari pandangan Stufflebeam, kita dapat melihat bahwa esensi dari evaluasi yakni memberikan informasi bagi kepentingan pengambilan keputusan. Di bidang pendidikan, kita dapat melakukan evaluasi terhadap kurikulum baru, suatu kebijakan pendidikan, sumber belajar tertentu, atau etos kerja guru.

Linn \& Gronlund (Sudrajad, 2011) mengemukakan' "tes adalah cara penilaian yang dirancang dan dilaksanakan kepada peserta didik pada waktu dan tempat tertentu serta dalam kondisi yang memenuhi syarat-syarat tertentu yang jelas”. Di satu sisi Mardapi (2014) menambahkan bahwa tes merupakan sejumlah pertanyaan yang memiliki jawaban benar atau salah. Secara lebih lengkap, Lee J. Cronbach menambahkan bahwa tes adalah " a systematic procedure for observing a person's behaviour and describing it with the aid of a numerical scale or a category system". (www.evaluasipendidikan). Penilaian (assessment) adalah penerapan berbagai cara dan penggunaan beragam alat penilaian untuk memperoleh informasi tentang sejauh mana hasil belajar peserta didik atau ketercapaian kompetensi (rangkaian kemampuan) peserta didik. 


\subsection{Tes Hasil Belajar (THB)}

Ada dua cara yang sering digunakan untuk mengukur aspek psikologi seseorang termasuk belajar yaitu dengan tes dan nontes. Sebagai salah satu alat untuk mengkuantifikasi sampel prilaku, maka para ahli memberikan berbagai macam klasifikasi tes yang berbeda tergantung perspektif sang ahli tersebut. Beberapa klasifikasi tersebut disebutkan di bawah ini. Cangelosi (Sujana, 2011) membedakan tes menjadi 2 buah yaitu tes baku dan tes buatan guru. Suryabrata (2011) membuat penggolongan tes berdasarkan atribut psikologis menjadi : (1) tes kepribadian, (2) tes inteligensi, (3) tes potensi intelektual dan (4) tes hasil belajar. Klasifikasi tes yang lebih lengkap disampaikan oleh Sudijono (2015) yang mengklasifikasikan tes berdasarkan perspektif tertentu. Jika tes digolongkan berdasarkan fungsi sebagai alat ukur perkembangan, maka ada 6 jenis tes yaitu tes seleksi, tes awal, tes akhir, tes diagnostik, tes formatif dan tes sumatif.

Setiap kegiatan belajar harus diketahui sejauhmana proses belajar tersebut telah memberikan nilai tambah bagi kemampuan siswa. Salah satu cara untuk melihat peningkatan kemampuan tersebut adalah dengan melakukan tes. Tes yang berkaitan dengan tujuan ini sering disebut tes hasil belajar (THB). Saifuddin (2003) menyatakan bahwa tes hasil belajar adalah tes yang disusun secara terencana untuk mengungkap informasi subyek atas bahan-bahan yang telah diajarkan. Menurut Sudijono (2005) "tes prestasi hasil belajar adalah tes yang digunakan untuk mengungkap tingkat pencapaian belajar". Dari beberapa pengertian di atas, ada satu kejelasan bahwa tes hasil belajar merupakan salah satu cara untuk menelusuri kemampuankemampuan yang telah dimiliki siswa setelah mengikuti proses belajar mengajar selama waktu tertentu. Meskipun tes bukanlah satu-satunya cara untuk mengungkap hasil belajar siswa, melainkan ia merupakan alat yang paling sering digunakan karena kepraktisan penggunaannya serta biaya yang murah.

Sapari (2012) mengemukakan bahwa tujuan pembelajaran pada hakikatnya adalah perubahan tingkah laku pada diri siswa. Oleh sebab itu dalam penilaian hendaknya diperiksa sejauh mana perubahan tingkah laku siswa telah terjadi melalui proses belajarnya. Lebih lanjut, Kemdikbud (2018) dikemukakan beberapa prinsip penilaian antara lain sebagai berikut : Penilaian hasil belajar hendaknya menjadi bagian integral dari proses pembelajaran. Penilaian hasil belajar hendaknya dirancang dengan jelas kemampuan apa yang harus dinilai, materi atau isi bahan ajar yang diujikan. Penilaian harus dilaksanakan secara komprehensif. Alat penilaian harus valid dan reliabel. Penilaian hasil belajar hendaknya diikuti dengan tidak lanjutnya. Penilaian hasil belajar harus objektif dan adil sehingga bisa mengambarkan emampuan siswa yang sebenarnya. 


\subsection{HOTS (High Order Thinking Skill)}

Soal-soal HOTS merupakan instrumen pengukuran yang digunakan untuk mengukur kemampuan berpikir tingkat tinggi. Soal-soal HOTS pada konteks asesmen, secara sederhana bukan hanya meminimalisir kemampuan mengingat kembali informasi (recall), tetapi lebih mengukur kemampuan: 1) transfer satu konsep ke konsep lainnya, 2) memproses dan menerapkan informasi, 3) mencari kaitan dari berbagai informasi yang berbeda-beda, 4) menggunakan informasi untuk menyelesaikan masalah, dan 5) menelaah ide dan informasi secara kritis. Meskipun demikian, soal-soal yang berbasis HOTS tidak berarti soal yang lebih sulit daripada soal recall.

Keterampilan berpikir tingkat tinggi atau High Order Thinking Skill (HOTS) adalah proses berfikir kompleks dalam menguraikan materi, membuat kesimpulan, membangun representasi, mengnalisis, dan membangun hubungan dengan melibatkan aktivitas mental yang paling dasar (Brookhart, 2010). Anderson \& Krathwohl (2001) mengklasifikasi dimensi proses kognitif disajikan pada Tabel 1 berikut.

Tabel 1. Dimensi Proses Kognitif

\begin{tabular}{|c|c|c|}
\hline Kategori & Domain & Keterangan \\
\hline HOTS & $\begin{array}{l}\text { Mengkreasi } \\
\text { Mengevaluasi } \\
\text { Menganalisis }\end{array}$ & $\begin{array}{l}\text { Mengkreasi ide/gagasan sendiri. } \\
\text { Mengambil keputusan sendiri. } \\
\text { Menspesifikasi aspek-aspek/elemen. }\end{array}$ \\
\hline MOTS & $\begin{array}{l}\text { Mengaplikasi } \\
\text { Memahami }\end{array}$ & $\begin{array}{l}\text { Menggunakan informasi pada } \\
\text { domain berbeda } \\
\text { Menjelaskan ide/konsep. }\end{array}$ \\
\hline LOTS & Mengetahui & Mengingat kembali. \\
\hline
\end{tabular}

Berdasarkan pendapat Anderson \& Krathwohl (2001) di atas, maka domain proses kognitif yang termasuk dalam kemampuan berpikir tingkat tinggi (Higher Order Thinking Skills/HOTS) adalah domain analisis (analyze), evaluasi (evaluate), dan mencipta (create). Domain proses kognitif tersebut yang digunakan sebagai salah satu acuan untuk menyusun soal-soal HOTS.

\subsection{Karakteristik Soal-Soal HOTS}

Karakteristik soal-soal HOTS sesuai dengan pengembangan model-model penilaian yang mengarahkan peserta didik untuk memiliki kemampuan berpikir tingkat tinggi, cerdas, kreatif, serta mampu berkontribusi dalam peradaban dunia. Adapun karakteristik soal-soal HOTS adalah sebagai berikut: Mengukur kemampuan berpikir tingkat tinggi, Berbasis permasalahan kontekstual, Menggunakan bentuk soal beragam. Pada umumnya langkahlangkah penulisan butir soal HOTS sama dengan langkah-langkah penyusunan butir soal lainnya. Berikut dipaparkan langkah-langkah penyusunan soal-soal HOTS: (1) Menganalisis 
KI-KD yang dapat dibuat soal-soal HOTS, (2) Menyusun kisi-kisi soal, (3) Menulis butir pertanyaan sesuai dengan kisi-kisi soal, dan (4) Membuat pedoman penskoran (rubrik) untuk bentuk soal jawaban singkat.

Berdasarkan uraian-uraian sebelumnya, maka dirumuskan masalah penelitian ini yaitu:

1. Bagaimana kualitas soal tes hasil belajar bahasa Indonesia buatan guru SDN 205 Inpres Moncongjai Kabupaten Maros ditilihat dari kaidah penulisan soal yang baik?

2. Bagaimana kualitas soal tes hasil belajar bahasa Indonesia buatan guru SDN 205 Inpres Moncongjai Kabupaten Maros ditilihat dari HOTS?

\section{Metode Penelitian}

Penelitian ini merupakan penelitian deskriptif kualitatif yang bersifat dokumentatif. Penelitian deskriptif kualitatif yaitu penelitian yang berusaha menggambarkan kondisi dan objek penelitian secara mendetail. Sugiyono (2014) menyatakan bahwa penelitian deskriptif itu dilakukan untuk mengetahui nilai variabel mandiri tanpa membuat perbandingan atau menghubungkan dua atau lebih variabel. Penelitian ini dilakukan di SDN 205 Inpres Moncongjai Kabupaten Maros. Dalam penelitian ini, dibahas secara deskriptif dan menganalisis secara mendalam tentang teks atau dokumen soal tes hasil belajar buatan guru mata pelajaran Bahasa Indonesia di SDN 205 Inpres Moncongjai Kabupaten Maros.

Analisis dalam penelitian ini yaitu dokumen tes buatan guru untuk ulangan akhir semester (UAS) SDN 205 Inpres Moncongjai Kabupaten Maros sebanyak tiga paket yaitu kelas IV, V dan VI semester ganjil tahun pelajaran 2018/2019. Penelitian ini hanya berfokus pada salah satu kompetensi guru dalam pembelajaran yaitu menulis soal khususnya mata pelajaran Bahasa Indonesia. Penentuan informa dibatasi hanya teks buatan guru pada kelas IV-VI dengan pertimbangan tingkat HOTS soal. Data dikumpulkan dengan teknik analisis dokumen, yakni peneliti melakukan pencatatan mengenai kualitas soal yang dibuat oleh guru. Dalam pencatatan ini didasarkan pada instrumen pedoman analisis soal dan karakteristik HOTS yang berisi kaidah yang seharusnya diterapkan dalam penulisan soal yang baik. Adapun data yang terkumpul sebagai data primer diperoleh dokumentasi berupa teks dalam bentuk kata-kata atau kalimat yang bersumber dari paket soal buatan guru.

Analisis data dalam penelitian ini dilakukan dengan analisis wacana atau teks berdasarkan kaidah penulisan soal Dalam penelitian ini, data yang terkumpul akan dianalisis secara kualitatif setelah melalui reduksi dan klasifikasi data dengan persentase. Perlu dijelaskan bahwa teknik persentase dilakukan hanya sebagai dasar dan penunjang untuk menginterpretasi dan mendeskripsikan data secara mendetail. 


\section{Hasil dan Pembahasan}

\subsection{Hasil Penelitian}

Pada bagian ini, hasil penelitian dengan memaparkan bukti empiris yang diperoleh pada penelitian yang telah dilakukan. Pemaparan ini merujuk pada rumusan masalah yang telah dikemukakan yaitu, (1) Bagaimana kualitas soal tes hasil belajar bahasa Indonesia buatan guru SDN 205 Inpres Moncongjai Kabupaten Maros ditilihat dari kaidah penulisan soal yang baik?, (2) Bagaimana kualitas soal tes hasil belajar bahasa Indonesia buatan guru SDN 205 Inpres Moncongjai Kabupaten Maros ditilihat dari HOTS? (3) Kaidah penulisan soal apa saja yang dominan tidak sesuai dengan kaidah penulisan soal yang baik pada soal tes hasil belajar bahasa Indonesia buatan guru SDN 205 Inpres Moncongjai Kabupaten Maros?

Data hasil penelitian ini berupa tealaah teks yang menurut kaidah penulisan soal tidak tepat atau keliru serta muatan unsur HOTS. Kekeliruan tersebut pada kaidah tertentu yang akan diuraikan secara kualitas dalam menyatakan kekeliruannya. Data tersebut dilihat pada aspek kaidah berkaitan dengan materi, kaidah konstruksi soal, kaidah berkaitan dengan bahasa soal, dan aspek berkaitan dengan Higher Order Thinking Skill (HOTS). Soal-soal buatan guru ditelaah menggunakan tabel telaah soal dalam bentuk matrik yang biasa digunakan sebagai kartu telaah soal.

\section{Telaah 1}

$\begin{array}{ll}\text { Jenis Penilaian } & : \text { Penilaian Akhir Semester (PAS) } \\ \text { Kelas } & : \text { IV } \\ \text { Semster } & : \text { Ganjil } \\ \text { Tahun Pelajaran } & : 2018 / 2019 \\ \text { Jumlah Butir Soal } & : 10 \\ \text { Bentuk soal } & : \text { Pilihan Ganda }\end{array}$

Berikut ini disajikan hasil analisis soal Penilaian Akhir Semester (PAS) kelas IV pada Tabel 2.

Tabel 2. Analisis Soal PAS Kelas IV

\begin{tabular}{|c|c|c|c|c|c|c|c|c|c|c|}
\hline \multirow{2}{*}{ Aspek } & \multicolumn{10}{|c|}{ Nomor Soal } \\
\hline & 1 & 2 & 3 & 4 & 5 & 6 & 7 & 8 & 9 & 10 \\
\hline 1 & 1 & 1 & 1 & 1 & 1 & 1 & 1 & 1 & 1 & 1 \\
\hline 2 & 1 & 1 & 1 & 1 & 1 & 1 & 1 & 1 & 1 & 1 \\
\hline 3 & 1 & 1 & 1 & 1 & 1 & 1 & 1 & 1 & 1 & 1 \\
\hline 4 & 1 & 1 & 1 & 1 & 1 & 1 & 1 & 1 & 1 & 1 \\
\hline 5 & 1 & 1 & 1 & 1 & 1 & 1 & 1 & 1 & 1 & 1 \\
\hline 6 & 1 & 1 & 1 & 1 & 1 & 0 & 1 & 1 & 0 & 1 \\
\hline
\end{tabular}




\begin{tabular}{ccccccccccc}
\hline \multirow{2}{*}{ Aspek } & \multicolumn{10}{c}{ Nomor Soal } \\
\cline { 2 - 10 } & $\mathbf{1}$ & $\mathbf{2}$ & $\mathbf{3}$ & $\mathbf{4}$ & $\mathbf{5}$ & $\mathbf{6}$ & $\mathbf{7}$ & $\mathbf{8}$ & $\mathbf{9}$ & $\mathbf{1 0}$ \\
\hline 7 & 1 & 1 & 1 & 1 & 1 & 1 & 1 & 1 & 0 & 0 \\
8 & 1 & 1 & 0 & 1 & 1 & 1 & 1 & 0 & 0 & 1 \\
9 & 1 & 1 & 1 & 1 & 1 & 1 & 1 & 1 & 1 & 1 \\
10 & 1 & 1 & 1 & 1 & 1 & 1 & 1 & 1 & 1 & 1 \\
11 & 1 & 1 & 1 & 1 & 1 & 1 & 1 & 0 & 1 & 1 \\
12 & 1 & 1 & 1 & 1 & 1 & 1 & 1 & 1 & 1 & 1 \\
13 & 1 & 1 & 1 & 1 & 1 & 1 & 1 & 1 & 1 & 1 \\
14 & 1 & 1 & 1 & 1 & 1 & 1 & 1 & 1 & 1 & 1 \\
15 & 1 & 1 & 1 & 1 & 1 & 1 & 1 & 1 & 1 & 1 \\
16 & 1 & 1 & 1 & 1 & 1 & 1 & 1 & 1 & 1 & 1 \\
17 & 0 & 0 & 0 & 0 & 0 & 0 & 0 & 0 & 0 & 0 \\
18 & 0 & 0 & 0 & 0 & 0 & 0 & 0 & 0 & 0 & 0 \\
19 & 0 & 0 & 0 & 0 & 0 & 0 & 0 & 0 & 0 & 0 \\
\hline
\end{tabular}

Catatan: 1: sesuai kaidah dan 0: tidak sesuai kaidah

Berdasarakan data Tabel 2 di atas dapat dijelaskan bahwa seluruh soal (10 soal) pilihan ganda pada umumnya sudah memenuhi krteria penulisan soal pilihan ganda yang baik. Namun, ada bebraoa kaidah yang tidak dipenuhi seperti: Pilihan jawaban harus homogen dan logis ditinjau dari segi isi materi: Panjang rumusan pilihan jawaban relatif sama; Pilihan jawaban jangan mengandung pernyataan yang berbunyi: Semua jawaban di atas salah atau semua jawaban di atas benar;. Khusus kadidah menggunakan bahasa yang sesuai kaidah bahasa Indonesia (semua aspek) semua soal memperlihatkan ketidaksesuaian lkaidah. Demikian halnya HOTS semua soal belum HOTS. Untuk lebih jelasnya dapat dilihat pada urian berikut berdasarkan butir soal.

\section{Telaah 2}

Jenis Penilaian $\quad$ : Penilaian Akhir Semester (PAS)

Kelas : $\mathrm{V}$

Semster : Ganjil

Tahun Pelajaran : :2018/2019

Jumlah Butir Soal $\quad$ : 10

Bentuk soal : Pilihan Ganda

Berikut ini disajikan hasil analisis soal Penilaian Akhir Semester (PAS) kelas V pada Tabel 3.

Tabel 3. Analisis Soal PAS Kelas V

\begin{tabular}{cccccccccccc}
\hline \multirow{3}{*}{ Aspek } & \multicolumn{10}{c}{ Nomor Soal } \\
\cline { 2 - 11 } & $\mathbf{1}$ & $\mathbf{2}$ & $\mathbf{3}$ & $\mathbf{4}$ & $\mathbf{5}$ & $\mathbf{6}$ & $\mathbf{7}$ & $\mathbf{8}$ & $\mathbf{9}$ & $\mathbf{1 0}$ \\
\hline 1 & 1 & 1 & 1 & 1 & 1 & 1 & 1 & 1 & 1 & 1 \\
\hline
\end{tabular}




\begin{tabular}{ccccccccccc}
\hline \multirow{2}{*}{ Aspek } & \multicolumn{10}{c}{ Nomor Soal } \\
\cline { 2 - 10 } & $\mathbf{1}$ & $\mathbf{2}$ & $\mathbf{3}$ & $\mathbf{4}$ & $\mathbf{5}$ & $\mathbf{6}$ & $\mathbf{7}$ & $\mathbf{8}$ & $\mathbf{9}$ & $\mathbf{1 0}$ \\
\hline 2 & 1 & 1 & 1 & 1 & 1 & 1 & 1 & 0 & 1 & 1 \\
3 & 1 & 1 & 1 & 1 & 1 & 1 & 1 & 1 & 1 & 1 \\
4 & 1 & 1 & 1 & 1 & 1 & 1 & 1 & 1 & 1 & 1 \\
5 & 1 & 1 & 1 & 1 & 1 & 1 & 1 & 1 & 1 & 1 \\
6 & 1 & 1 & 1 & 1 & 1 & 1 & 1 & 1 & 0 & 1 \\
7 & 1 & 1 & 1 & 1 & 1 & 1 & 1 & 1 & 1 & 1 \\
8 & 1 & 1 & 1 & 1 & 1 & 1 & 1 & 1 & 1 & 1 \\
9 & 1 & 1 & 1 & 1 & 1 & 1 & 1 & 1 & 1 & 1 \\
10 & 1 & 1 & 1 & 1 & 1 & 1 & 1 & 1 & 1 & 1 \\
11 & 1 & 1 & 1 & 1 & 1 & 1 & 1 & 0 & 1 & 1 \\
12 & 1 & 1 & 1 & 1 & 1 & 1 & 1 & 1 & 1 & 1 \\
13 & 1 & 1 & 1 & 1 & 1 & 1 & 1 & 1 & 1 & 1 \\
14 & 1 & 1 & 1 & 1 & 1 & 1 & 1 & 1 & 1 & 1 \\
15 & 1 & 1 & 1 & 1 & 1 & 1 & 1 & 1 & 1 & 1 \\
16 & 1 & 1 & 1 & 1 & 1 & 1 & 1 & 1 & 1 & 1 \\
17 & 0 & 0 & 0 & 0 & 0 & 1 & 0 & 0 & 0 & 0 \\
18 & 0 & 0 & 0 & 1 & 0 & 1 & 0 & 0 & 0 & 0 \\
19 & 0 & 0 & 0 & 1 & 0 & 0 & 0 & 1 & 0 & 0 \\
\hline
\end{tabular}

Catatan: 1: sesuai kaidah dan 0: tidak sesuai kaidah

Berdasarakan data tabel 3 di atas dapat dijelaskan bahwa seluruh soal (10 soal) pilihan ganda pada umumnya sudah memenuhi kriteria penulisan soal pilihan ganda yang baik, namun, ada beberapa kaidah yang tidak dipenuhi. Khusus kaidah menggunakan bahasa yang sesuai kaidah bahasa Indonesia (semua aspek) hampir semua soal memperlihatkan ketidaksesuaian kaidah. Demikian halnya HOTS semua soal belum HOTS.

\section{Telaah 3}

Jenis Penilaian $\quad$ : Penilaian Akhir Semester (PAS)

Kelas : VI

Semster : : Ganjil

Tahun Pelajaran : : 2018/2019

Jumlah Butir Soal : : 10

Bentuk soal : Pilihan Ganda

Berikut ini disajikan hasil analisis soal Penilaian Akhir Semester (PAS) kelas V pada Tabel 4.

Tabel 4. Analisis Soal PAS Kelas V

\begin{tabular}{ccccccccccc}
\hline \multirow{2}{*}{ Aspek } & \multicolumn{10}{c}{ Nomor Soal } \\
\cline { 2 - 13 } & $\mathbf{1}$ & $\mathbf{2}$ & $\mathbf{3}$ & $\mathbf{4}$ & $\mathbf{5}$ & $\mathbf{6}$ & $\mathbf{7}$ & $\mathbf{8}$ & $\mathbf{9}$ & $\mathbf{1 0}$ \\
\hline 1 & 1 & 1 & 1 & 1 & 1 & 1 & 1 & 1 & 1 & 1 \\
\hline
\end{tabular}




\begin{tabular}{lllllllllll}
\hline 2 & 1 & 1 & 1 & 1 & 1 & 1 & 1 & 0 & 1 & 1 \\
3 & 1 & 1 & 1 & 1 & 1 & 1 & 1 & 1 & 1 & 1 \\
4 & 1 & 1 & 1 & 1 & 1 & 1 & 1 & 1 & 1 & 1 \\
5 & 1 & 1 & 1 & 1 & 1 & 1 & 1 & 1 & 1 & 1 \\
6 & 1 & 1 & 1 & 1 & 1 & 1 & 1 & 1 & 1 & 0 \\
7 & 1 & 1 & 1 & 1 & 1 & 1 & 1 & 1 & 1 & 1 \\
8 & 1 & 1 & 1 & 1 & 1 & 1 & 1 & 1 & 1 & 1 \\
9 & 1 & 1 & 1 & 1 & 1 & 1 & 1 & 1 & 1 & 1 \\
10 & 1 & 1 & 1 & 1 & 1 & 1 & 1 & 1 & 1 & 1 \\
11 & 1 & 1 & 1 & 1 & 1 & 1 & 1 & 1 & 1 & 1 \\
12 & 1 & 1 & 1 & 1 & 1 & 1 & 1 & 1 & 1 & 1 \\
13 & 1 & 1 & 1 & 1 & 1 & 1 & 1 & 1 & 1 & 1 \\
14 & 1 & 1 & 1 & 1 & 1 & 1 & 1 & 1 & 1 & 1 \\
15 & 1 & 1 & 1 & 1 & 1 & 1 & 1 & 1 & 1 & 1 \\
16 & 1 & 1 & 1 & 1 & 1 & 1 & 1 & 1 & 1 & 1 \\
17 & 1 & 1 & 1 & 1 & 0 & 1 & 0 & 0 & 1 & 1 \\
18 & 0 & 1 & 0 & 1 & 1 & 1 & 1 & 0 & 1 & 1 \\
19 & 0 & 1 & 0 & 1 & 1 & 1 & 1 & 1 & 1 & 1 \\
\hline
\end{tabular}

Catatan: 1: sesuai kaidah dan 0:tidak sesuai kaidah

Berdasarakan data tabel 4 di atas dapat dijelaskan bahwa seluruh soal (10 soal) pilihan ganda pada umumnya sudah memenuhi krteria penulisan soal pilihan ganda yang baik, namun, ada beberapa kaidah yang tidak dipenuhi. Khusus kaidah menggunakan bahasa yang sesuai kaidah bahasa Indonesia (semua aspek) hampir semua soal memperlihatkan ketidaksesuaian kaidah. Demikian halnya HOTS semua soal belum HOTS.

\subsection{Pembahasan}

Berdasarakan hasil analisis data di atas dijelaskan bahwa seluruh soal tes hasil belajar bahasa Indonesia buatan guru SDN 205 Inpres Moncongjai Kabupaten Maros dari tiga tingkatan kelas, yaitu kelas VI, V, dan VI pada umumnya belum memenuhi kriteria penulisan soal yang baik, terutama ada beberapa kaidah yang sulit dipenuhi tetapi kaidah tertentu yang sudah dapat dipenuhi.

Butir soal yang tidak sesuai kaidah umumnya terjadi pada kaidah berikut.

1. Soal harus sesuai dengan indikator. Butir soal yang tidak sesuai kaidah ini hanya da satu soal, sisanya sudah sesuai.

2. Pilihan jawaban harus homogen dan logis ditinjau dari segi isi materi. Bebebrapa soal tidak sesuai dengan kaidah ini seperti menuliskan pilihan jawab yang tidak semua positif, atau karakteristik pilihan jawaban tidak sama.

3. Panjang rumusan pilihan jawaban relatif sama. Ada juga butir soal yang tidak sesuai 
dengan kaidah ini sehingga, sangat mudah ditebak jawaban dariu soal tersebut.

4. Pilihan jawaban jangan mengandung pernyataan yang berbunyi: Semua jawaban di atas salah atau semua jawaban di atas benar. Butir soal yang tidak sesuai dengan kaidah ini ada beberap yang menyatakan pada pilihan jawaban a,b, c benar. Hal ini tentu kuncinya tidak tepat.

5. Gambar, grafik, tabel diagram, atau sejenisnya yang terdapat pada soal harus jelas dan berfungsi. Ada beberapa butir soal yang tidak memenuhi kaidah ini seperti soal yang tidak menggunakan nomor pada gambar sehingga tidak jelas pemanfaatan hgambar dalam soal.

6. Menggunakan bahasa yang sesuai kaidah bahasa Indonesia (semua aspek). Kaidah ini sangat banyak dilanggar dalam p butir soal yang dianalisis. Umumnya kesalahan terjadi pada butir soal adalah kaidah penggunaan tanda baca elipsis (...). Tanda elipsis (...) dipergunakan untuk mengganti teks yang dihilangkan di tengah dan awal kalimat, dan akhir. Tanda titik (.) digunakan pada akhir kalimat atau akhir pernyataan soal harus dirangkai dengan tanda elipsis (...) yang mengikutinya, tidak diperkenankan diberi jarak. Pokok soal yang tidak diakhiri pilihan jawaban yang menggunakan tanda titik, tanda tanya, dan tanda seru menggunakan 4 titik (satu elipsis dan satu titik untuk akhir kalimat). Tanda titik (.) digunakan pada akhir pilihan jawaban (option) apabila terjadi hal-hal berikut. (1) pilihan jawaban berbentuk kalimat, (2) pilihan jawaban berbentuk pernyataan, (3) pilihan jawaban berbentuk kutipan peraturan-peranturan. Berdasarkan kaidah tersebut maka soal di atas menyalahi kaidah bahasa tentang elipisis. Selain itu, juga terjadi beberapa kekeliruan penggunaan bahsa pada penulisan huruf kapital, penulisan kata depan di, dan sebagainya.

7. Mengukur C4, C5 atau C6. Tingkat berpikir soal bahasa Indonesia Indonesia buatan guru SDN 205 Inpres Moncongjai Kabupaten Maros umumnya belum belum berpikir tingkat tionggi (HOTS). Hanya sedirkit yuang menggunakan tingkat berpikir penalaran ( $\mathrm{C} 4, \mathrm{C} 5$, dan $\mathrm{C} 6)$. Umumnya hanya menggunakan $\mathrm{C} 1, \mathrm{C} 2$, dan C3.

8. Berbasis permasalahan kontekstual. Untuk menuju soal HOTS sebaiknya soal menggunakan permasalahan kontekstual. Hal ini sudah ada bebertap soal yang memuat inin, namun masih sangat terbatas.

Hasil penelitian ini menggambarkan bahwa pemahaman mengenai kaidah penulisan soal sangat penting. Hal ini telah ditegaskan oleh Harun (2011) Kaidah penulisan soal 
merupakan petunjuk atau pedoman yang perlu diikuti penulis agar soal yang dihasilkan memiliki mutu yang baik. Soal yang memiliki mutu baik adalah soal yang mampu menjaring informasi yang diperlukan dan ber $\neg$ fungsi secara optimal. Kaidah-kaidah penulisan soal meliputi segi materi, kon $\neg$ strnksi soal dan segi bahasa. Hal ini juga ditegaskan oleh Suryabrata (2015) bahawa soal yang baik adalah memenuhi kaidah penulisan soal. Soal yang baik adalah soal yang dapat dijawab oleh soswa dengan pemamahaman yang tepat, tidak sulit menafsirkan maknanya. Sudijono (2015) menegaskan bahwa soal yang kurang baik (tidak sesuai dengan kaidah penulisan soal, maka memungkinkan siswa kesulitan menafsirkan makna soal sehingga sulit menjawab. Tes hasil belajar harus jelas maknanya oleh peserta tes. Oleh karena itu, penulis soal harus memahami dengan baik kaidah penulis soal. Azwar (2014) mengemukkaan bahwa salah satu persyaratan penulis soal ada memahami kaidah penulisan soal. Penulis soal tidak hanya dituntut menguasai materi tes tetapi harus terampil menyusun tes berdasrkan kaidah penulisan soal. Oleh karen aitu latihan menulis soal sama dengan latihan menulis karangan.

Selain itu, untuk mengembangakan kemampuan berpikir tingkat tinggai seperi berpikir kritis, berpikir analitik, berpikir evaluatif serta mengkreasi sesuatu, maka dibutuhkan kebiasaan menjawab soal-soal berbasis HOTS. Kebiasaan menjawab soal HOTS, berdampak pada kemampuan siswa memecahkan masalah dalam kehdupan sehari-hari.

\section{Kesimpulan}

Berdasarkan analisis dan pembahasan hasil penelitian, dikemukakan beberapa kesimpulan sebagai berikut.

a. Kualitas soal tes hasil belajar bahasa Indonesia buatan guru SDN 205 Inpres Moncongjai Kabupaten Maros ditilihat dari kaidah penulisan soal yang baikmasih rendah. Kaidah penulisan soal dominan tidak sesuai adalah (1) kaidah soal harus menggunakan bahasa yang sesuai kaidah bahasa Indonesia (semua aspek) (2) pilihan jawaban harus homogen dan logis ditinjau dari segi isi materi.

b. Soal tes hasil belajar bahasa Indonesia buatan guru SDN 205 Inpres Moncongjai Kabupaten Maros masih sangat sedikit yang berbasis HOTS. Pada level tingkat berpikir soal umunya masih berada pada ingatan, pemahamn dan penerapan, masih sangat sedikit yang berbasis HOTS.

\section{DAFTAR PUSTAKA}

Ahmad, S., Prahmana, R. C. I., Kenedi, A. K., Helsa, Y., Arianil, Y., \& Zainil, M. (2017). The instruments of higher order thinking skills. In Journal of Physics: Conference Series (Vol. 
943, No. 1, p. 012053). IOP Publishing.

Anderson, L. W., \& Krathwohl, D. R. (2001). A taxonomy for learning, teaching, and assessing: A revision of Bloom's taxonomy of educational objectives. Longman.

Astuti, N. K. G., Dibia, I. K., \& Sudarma, I. K. (2021). Instrumen Penilaian Hasil Belajar Berbasis Higher Order Thinking Skill Pada Tema Kepemimpinan. Mimbar Ilmu, 26(2).

Azwar, S. (2014). Penilaian Pembelajaran, Sebuah Pengantar. Jogjakarta: Analisa

Brookhart, S. M. (2010). How to assess higher-order thinking skills in your classroom. ASCD.

Bungin, B. (2011). Penilaian Hasil Belajar.Jakarta: Gema Press.

Heong, Y. M., Othman, W. B., Yunos, J. B. M., Kiong, T. T., Hassan, R. B., \& Mohamad, M. M. B. (2011). The level of marzano higher order thinking skills among technical education students. International Journal of Social Science and Humanity, 1(2), 121.

Hudiyono, Y., \& Ilyas, M. (2020). Pengembangan Instrumen Asesmen Higher Order Thinking Skills (HOTS) pada Mata Pelajaran Bahasa Indonesia SMA dan SMK. Diglosia: Jurnal Kajian Bahasa, Sastra, dan Pengajarannya, 3(1), 102-113.

Istiyono, E., Mardapi, D., \& Suparno, S. (2014). Pengembangan tes kemampuan berpikir tingkat tinggi fisika (pysthots) peserta didik SMA. Jurnal Penelitian dan Evaluasi Pendidikan, 18(1), 1-12.

Joy King F.J., Ludwika G., \& Faranak R. (2012). Higher Order Thinking Skills. Educational Service Program Publisher.

Kemedikbud, (2018). Pedoman Penilaian Sekolah Dasar. Jakarta: Dirjen TK SD

Kholiq, H. A., Artharina, F. P., \& Arisyanto, P. (2019). Analisis Penilaian Berorientasi Higher Order Thinking Skills siswa Kelas V. JANACITTA, 2(2).

Krathwohl, D. R. (2002). A revision of Bloom's taxonomy: An overview. Theory into practice, 41(4), 212-218.

Lathifah, D. A., \& Salamah, U. U. (2020, July). Model Pembelajaran Problem Based Learning Berkaitan Dengan Higher Order Thinking Skill Untuk Sekolah Dasar. In SEMINAR NASIONAL PENDIDIKAN DASAR (Vol. 2).

Mainali, B. P. (2012). Higher order thinking in education. Academic Voices: A Multidisciplinary Journal, 2, 5-10.

Makmun, S. (2016). Penilaian Kelas. Jakarta: Multi Aksara

Mardapi. (2014). Pengantar Penilaian Pendidikan. Bandung: Angkasa

Moleong, L. J. (2011). Metodologi Penelitian Kualitatif. (Cetakan ke-20). Bandung: Remaja Rosdakarya. 
Munadi, S. (2011). Analisis validasi kualitas soal tes hasil belajar pada pelaksanaan program pembelajaran. Jurnal Cakrawala Pendidikan, 1(1).

Permendikbud Nomor 104 Tahun 2014 tentang Penilaian Hasil Belajar Oleh Satuan Pendidikan.

Pratiwi, P. H., Hidayah, N., \& Martiana, A. (2017). Pengembangan modul mata kuliah penilaian pembelajaran sosiologi berorientasi HOTS. Cakrawala Pendidikan, (2), 85339.

Purwasi, L. A. (2019). The Development Of Higher-Order Thinking Skills On Junior High School Students Through Guided Inquiry-Based Learning Approach. Jurnal Pendidikan Matematika dan IPA, 11(2), 311-322.

Sapari, A. (2012). Penilaian Pendidikan. Yogyakarta: Analisis

Sudijono, A. (2015). Penilaian Hasil Belajar Siswa. Bandung: Angakasa

Sudrajad, A. (2011). Kurikulum dan Pengembangan Bahan Ajar. Online (http://evaluasipendidikan.com).

Sugiyono. (2014). Metode Penelitian Administrasi. (Cetakan ke-14). Bandung: Alfabeta.

Suhaesti Julianingsih, S. J., Undang Rosidin, U. R., \& Ismu Wahyudi, I. W. (2017). Pengembangan instrumen asesmen HOTS untuk mengukur dimensi pengetahuan IPA siswa di SMP. Jurnal Pembelajaran Fisika, 5(3).

Suryabrata, S. (2011). Penilaian Pendididikan. Jakarta: Pustaka Utama

Utami, S. A., \& Nurgiyantoro, B. (2016). Kualitas Soal Dan Daya Serap Tes Pendalaman Materi Un Bahasa Indonesia Smp Di Gunungkidul. Diksi, 24(1).

Yuliandini, N., Hamdu, G., \& Respati, R. (2019). Pengembangan soal tes berbasis higher order thinking skill (hots) taksonomi bloom revisi di sekolah dasar. PEDADIDAKTIKA: Jurnal Ilmiah Pendidikan Guru Sekolah Dasar, 6(1), 37-46. 